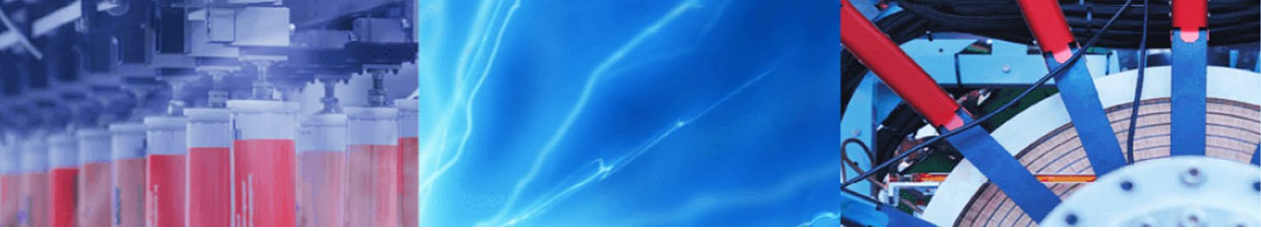

Research Article

\title{
Synthesis of red emitting triphenylamine derived NLOphoric D-ח-A molecules: photophysical, and viscosity sensing studies
}

\author{
Dinesh S. Patil ${ }^{1} \cdot$ Kiran C. Avhad $^{1} \cdot$ Mayuri M. Kadam ${ }^{1} \cdot$ Nagayain Sekar $^{1}$ (D)
}

(c) Springer Nature Switzerland AG 2019

\begin{abstract}
Four small dyes with triphenylamine (TPA) as a donor and various acceptor groups connected with $\pi$-linker having chloro group are synthesized and studied for solvatochromism and DFT. Good solvatochromism is observed in compounds $\mathbf{2}$ and $\mathbf{4}$ having TPA attached to rhodamine-3-acetic acid and 4-aminosalicylic acid. The multilinear regression analysis supports the solvatochromic behaviour of the chromophores. The compound $\mathbf{4}$ shows viscosity sensing with 0.57 viscosity sensitivity $(x)$ value as which is more as compared with the other compounds, and 14.14-fold increased emission intensity in viscous solution from 0 to $99 \%$ of PEG-400 in ethanol. These TPA based compounds 1, 2, 3, and 4 show two-photon absorption cross section in the range 702-1265 GM. The natural bond analysis shows charge transfer in compound having strong withdrawing groups, that is compound $\mathbf{1}$ and $\mathbf{2}$. The bond length alteration is correlated with the computationally obtained NLO properties and show linear correlation. The compound $\mathbf{1}$ is a better NLOphoric material than the other compound $\mathbf{2}, \mathbf{3}$, and $\mathbf{4}$ as revealed by solvatochromic and computational methods.
\end{abstract}

Keywords Triphenylamine · 4-aminosalicylic acid · Viscosity sensor ·TD-DFT · NLO · Accepting group

\section{Introduction}

Triphenylamine (TPA) is a planar aromatic compound and widely used as an electron donating unit in donor- $\pi$-acceptor (D- $\pi-A)$ framework [1-4]. TPA helps good charge transfer (CT) in several D- $\Pi-A$ dyes which are designed for various applications and it is widely used for the design of two photon absorption (2PA) chromophores [5-11]. TPA based $\mathrm{D}-\pi-\mathrm{A}$ framework have attract much more attention as the best electron transporting organic materials in dye sensitized solar cell (DSSC) due to their in expensive synthesis, outstanding stabilities, and high molar extinction coefficient [12-18]. A large number of TPA based chromophores are used for their applications in red to deep red organic light emitting diodes (OLEDs) [19-26]. The TPA has excellent intramolecular charge transfer (ICT) characteristics and it is attached to different electron withdrawing units for various applications [27-34]. TPA based dyes are also widely investigated for their good AIE properties [35-43].

Recently fluorescent molecular rotors (FMRs), a class of fluorescent dyes which undergo twisted intramolecular charge transfer (TICT) upon photo excitation increased much attention [44-46]. 9-(Dicyanovinyl)-julolidine (DCVJ) is the best example exhibiting viscosity sensitivity. Different TPA derivatives exhibit FMR properties due to the freely rotating phenyl ring which is hindered in the viscous media causing fluorescence enhancement [47]. The TICT states are responsible for quenching of fluorescence in polar solvents and show more emission in a highly viscous solution. The electron withdrawing groups also play a major role in D- $\pi-A$ systems used in DSSC and OLED, biological and FMR studies [48-52]. The functionalized carboxylic

Electronic supplementary material The online version of this article (https://doi.org/10.1007/s42452-019-0268-z) contains supplementary material, which is available to authorized users.

Nagayain Sekar, nethi.sekar@gmail.com; n.sekar@ictmumbai.edu.in | 'Department of Dyestuff Technology, Institute of Chemical Technology (ICT), Mumbai, Maharashtra 400 019, India.

SN Applied Sciences (2019) 1:259| https://doi.org/10.1007/s42452-019-0268-z 
acid having electron withdrawing group in conjugation is used as a standard accepting group in DSSC [53-58]. Recently fluorescent quantum dots have attracted much attention owing to their colorful fluorescence properties which can be widely used in the diagnosis of disease or cell detection (-COOH) [59]. Considerable effort is focused on fabricating fluorescent sensors for nucleic acid detection [59]. Herein, we developed a simple strategy having TPA as a donor and group containing $-\mathrm{COOH}$ as acceptor (except compound 3). Scheme 1 represents the structure of four chromophores studied.

For the first time 4-aminosalicylic acid as an acceptor group is employed in a Schiff base to explore superiority of Schiff base over conventional electron accepting groups. To understand the structural correlations and viscosity sensitivity of these dyes carrying different acceptor groups, we have synthesized four compounds having TPA based donor with chloro-group suitably placed on $\pi$-linker and cyanoacetic acid, rhodanine3-acetic acid, dicyanovinylene or 4-amino salicylic acid as acceptor as shown in Scheme 1. The photo physical properties of the all compounds are well studied. The HOMO and LUMO energy level diagrams were obtained by theoretical DFT calculation. Density functional theory (DFT) computations were used to study the geometrical and electronic properties of the synthesized $D-\pi-A$ dyes. The experimentally and theoretically calculated NLO properties of these chromophores showed that these chromophores are NLOphoric and have considerable two-photon absorption (2PA) cross section. The compound $\mathbf{4}$ behaves as good FMR with high viscosity sensitivity as compared to the known FMR, DCVJ.

\section{Experimental}

\subsection{Chemicals and instruments}

All the commercial reagents and the solvents were procured from S. D. Fine Chemicals Pvt Ltd. Mumbai and were used without purification. Triphenylamine was procured from Alfa Aeser. The reaction was monitored by TLC using $0.25 \mathrm{~mm}$ silica gel 60 F254 percolated plates, which were visualized with UV light. ${ }^{1} \mathrm{H}$ NMR and ${ }^{13} \mathrm{C}$ NMR spectra were recorded on Agilent $500 \mathrm{MHz}$ instrument (USA using TMS as an internal standard). The UV visible absorption spectra of the compounds $\mathbf{1}$, 2, 3, and 4 were recorded on a Perkins-Elmer Lambda 25 spectrometer; fluorescence emission spectra were recorded on Varian Cary Eclipse fluorescence spectrophotometer.

\subsection{Computational details}

Ground state geometries of the molecules were optimized using the DFT hybrid functional, B3LYP [62]. Pople's basis set with both diffuse and polarization functions, $6-311++G(d, p)$ was used for all the atoms. The B3LYP is a combination of Becke's three parameter exchange functional (B3) [63] with the nonlocal correlation functional by Lee, Yang, and Parr (LYP) [64]. The first excited singlet states were optimized using TD-DFT B3LYP and CAM-B3LYP/6-311++G(d,p). Frequency computations were carried out on the optimized geometry of the low-lying vibronically relaxed first excited state of molecules [65]. The TD-DFT calculations with B3LYP functional (the global hybrid) were performed and compared with the experimental data. The polarizable
Scheme 1 Chemical structure of the TPA based chromophores

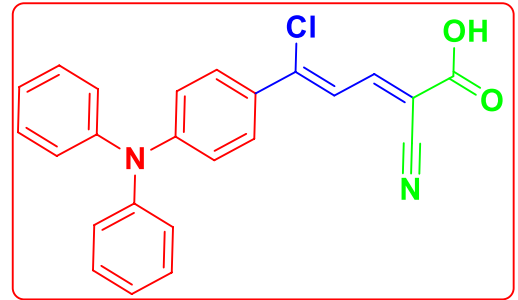

1

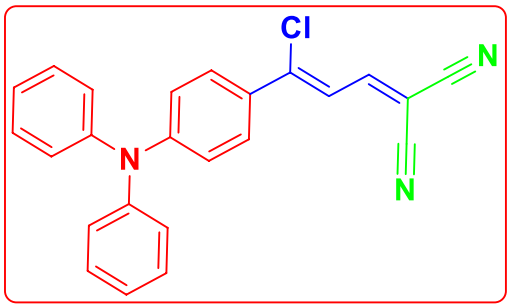

3

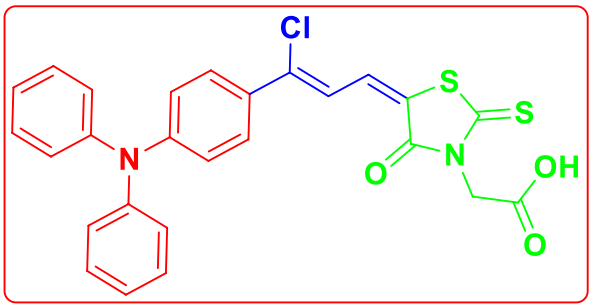

2

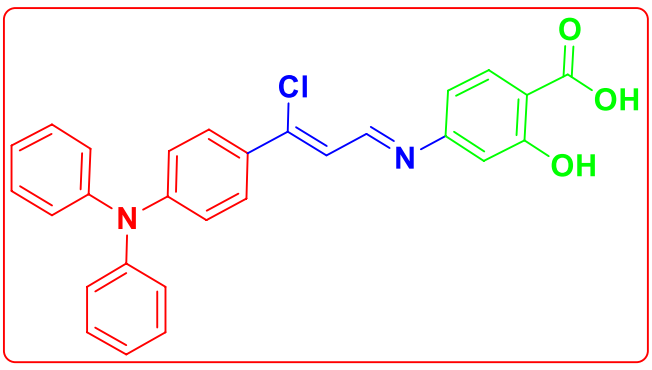

4

SN Applied Sciences 
continuum model (PCM) $[66,67]$ as implemented in Gaussian 09 was used for optimization in solvents. The Gaussian 09 [68] program was used for all the DFT and TD-DFT computation.

\section{Results and discussion}

\subsection{Synthesis and characterization}

Synthesis of intermediates and final dyes with purity was reported in our earlier paper [60] and also given in supporting information.

\subsection{Photophysical properties}

Absorption and emission properties of 1, 2, 3, and $\mathbf{4}$ are studied in various solvents with different polarities. Table 1 shows absorption and emission maxima, molar extinction coefficient, and Stokes shift of all the four chromophores in various solvents. Figure 1 represents normalized absorption and emission spectra for all the four chromophores in seven different solvents. The first absorption smaller peak at around $372 \mathrm{~nm}$ is due to the $\pi-\pi^{*}$ transition of compound $\mathbf{2}[61]$ and the second peak near $500 \mathrm{~nm}$ is due to the intramolecular charge transfer transition (ICT). The red shifted absorption spectra were observed when the rhodamine-3-acetic acid group is attached to triphenylamine
Table 1 Photophysical properties of the compounds in seven solvents

\begin{tabular}{|c|c|c|c|c|c|c|c|c|c|}
\hline \multirow[t]{2}{*}{ Solvent } & \multirow{2}{*}{$\begin{array}{l}\lambda_{\mathrm{abs}}^{\mathrm{a}} \\
(\mathrm{nm})\end{array}$} & \multirow{2}{*}{$\begin{array}{l}\varepsilon_{\max }^{b} \times 10^{4} \\
\left(\mathrm{M}^{-1} \mathrm{~cm}^{-1}\right)\end{array}$} & \multirow{2}{*}{$\begin{array}{l}\text { fwhm }^{c} \\
(\mathrm{~nm})\end{array}$} & \multirow{2}{*}{$\begin{array}{l}\lambda_{\text {ems }}^{d} \\
(n m)\end{array}$} & \multicolumn{2}{|c|}{ Stokes shift $\mathrm{e}^{\mathrm{e}}$} & \multirow[t]{2}{*}{$\Phi_{\mathrm{F}}^{f}$} & \multirow[t]{2}{*}{$f^{g}$} & \multirow{2}{*}{$\begin{array}{l}\mu_{e g}(\text { Abs })^{\mathrm{h}} \\
\text { (debye) }\end{array}$} \\
\hline & & & & & $\overline{(\mathrm{nm})}$ & $\left(\mathrm{cm}^{-1}\right)$ & & & \\
\hline \multicolumn{10}{|l|}{1} \\
\hline $\mathrm{CHCl}_{3}$ & 482 & 23.2 & 149 & 631 & 149 & 4899 & 0.039 & 4.68 & 22.17 \\
\hline$E A^{i}$ & 462 & 23.6 & 91 & 620 & 158 & 5515 & 0.033 & 4.95 & 22.09 \\
\hline Acetone & 479 & 21.4 & 102 & 588 & 109 & 3870 & 0.029 & 4.91 & 21.83 \\
\hline $\mathrm{ACN}$ & 474 & 14.0 & 177 & 567 & 93 & 3460 & 0.015 & 3.68 & 18.77 \\
\hline $\mathrm{MeOH}$ & 462 & 23.5 & 91 & 621 & 159 & 5541 & 0.009 & 4.95 & 22.08 \\
\hline DMF & 415 & 21.3 & 76 & 562 & 147 & 6302 & 0.019 & 4.64 & 20.40 \\
\hline DMSO & 473 & 22.4 & 89 & 628 & 155 & 5218 & 0.023 & 4.29 & 20.80 \\
\hline \multicolumn{10}{|l|}{2} \\
\hline $\mathrm{CHCl}_{3}$ & 497 & 12.0 & 96 & 638 & 141 & 4446 & 0.042 & 3.03 & 17.91 \\
\hline$E A^{i}$ & 483 & 12.9 & 92 & 626 & 143 & 4729 & 0.056 & 3.25 & 18.29 \\
\hline Acetone & 482 & 10.5 & 96 & 630 & 148 & 4873 & 0.039 & 2.50 & 16.04 \\
\hline $\mathrm{ACN}$ & 486 & 13.2 & 94 & 662 & 176 & 5470 & 0.024 & 3.24 & 18.32 \\
\hline $\mathrm{MeOH}$ & 488 & 11.8 & 99 & 673 & 185 & 5632 & 0.035 & 3.10 & 17.95 \\
\hline DMF & 485 & 13.4 & 97 & 653 & 168 & 5304 & 0.015 & 3.54 & 19.13 \\
\hline DMSO & 501 & 13.7 & 102 & 668 & 167 & 4990 & 0.038 & 3.61 & 19.63 \\
\hline \multicolumn{10}{|l|}{3} \\
\hline $\mathrm{CHCl}_{3}$ & 509 & 11.9 & 86 & 643 & 134 & 4094 & 0.034 & 2.07 & 14.99 \\
\hline$E A^{i}$ & 485 & 12.1 & 88 & 645 & 160 & 5114 & 0.031 & 2.51 & 16.11 \\
\hline Acetone & 488 & 11.4 & 95 & 617 & 129 & 4284 & 0.040 & 2.52 & 16.19 \\
\hline ACN & 486 & 10.2 & 93 & 595 & 109 & 3769 & 0.015 & 2.19 & 15.08 \\
\hline $\mathrm{MeOH}$ & 485 & 10.8 & 94 & 563 & 78 & 2856 & 0.029 & 2.46 & 15.95 \\
\hline DMF & 494 & 13.2 & 105 & 591 & 97 & 3322 & 0.032 & 3.86 & 20.16 \\
\hline DMSO & 497 & 12.3 & 99 & 633 & 136 & 4322 & 0.028 & 2.79 & 17.18 \\
\hline \multicolumn{10}{|l|}{4} \\
\hline $\mathrm{CHCl}_{3}$ & 375 & 6.0 & 52 & 456 & 81 & 4736 & 0.087 & 1.01 & 8.94 \\
\hline$E A^{i}$ & 370 & 6.6 & 46 & 441 & 71 & 4351 & 0.064 & 0.95 & 8.64 \\
\hline Acetone & 371 & 7.6 & 53 & 500 & 129 & 6954 & 0.045 & 1.34 & 10.29 \\
\hline $\mathrm{ACN}$ & 370 & 8.1 & 49 & 464 & 94 & 5475 & 0.041 & 1.20 & 9.72 \\
\hline $\mathrm{MeOH}$ & 369 & 7.0 & 51 & 484 & 115 & 6439 & 0.056 & 1.13 & 9.45 \\
\hline DMF & 374 & 6.6 & 48 & 474 & 100 & 5640 & 0.024 & 0.96 & 8.77 \\
\hline DMSO & 376 & 6.0 & 50 & 482 & 106 & 5848 & 0.028 & 0.89 & 8.45 \\
\hline
\end{tabular}

a absorption maxima, ${ }^{b}$ molar extension coefficient, ${ }^{c}$ full width half maxima, ${ }^{d}$ emission maxima, ${ }^{e}$ Stokes shift, fquantum yield, ${ }^{9}$ oscillator strength, hdipole moment and 'ethyl acetate 
moiety. Also, with the presence of strong electron accepting group cyanoacrylic acid in compound $\mathbf{1}$, are markable change in the molar extinction coefficient was observed
(Table 1). The chromophore having strong electron withdrawing group cyanoacetic acid (1) shows the highest molar extinction coefficient, while the chromophore
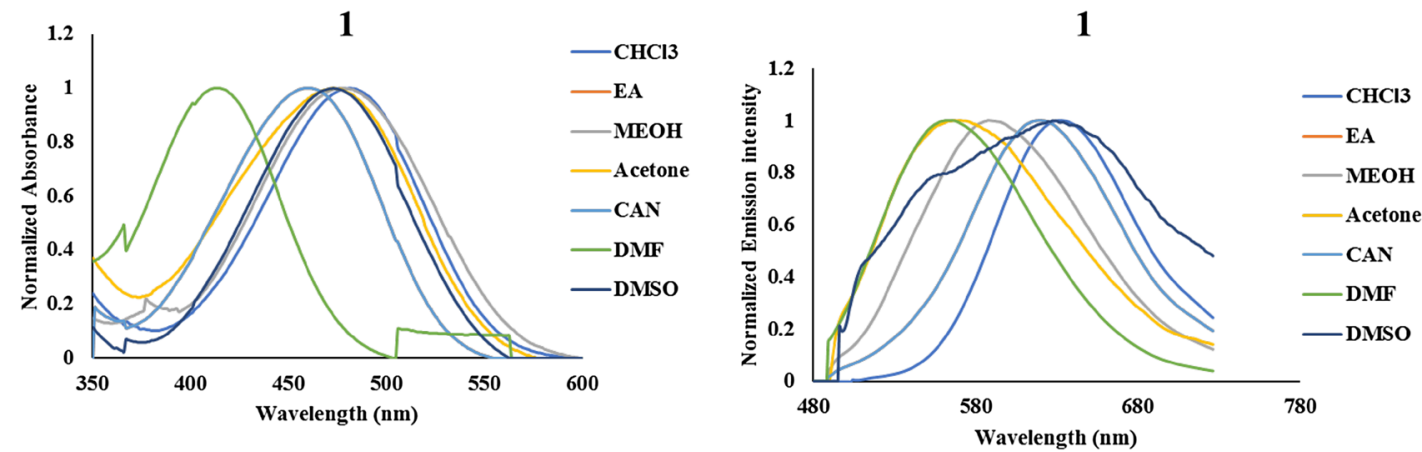

2

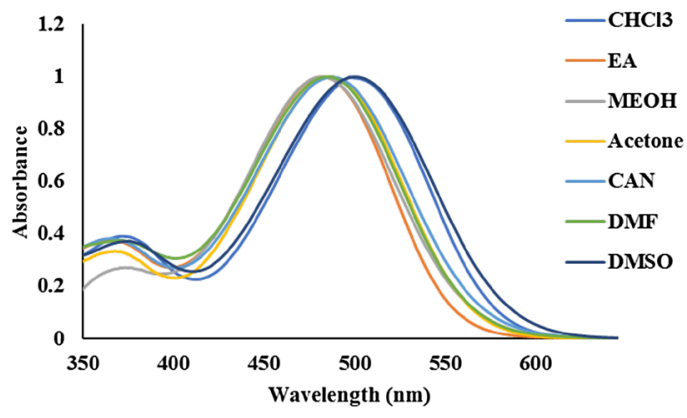

3

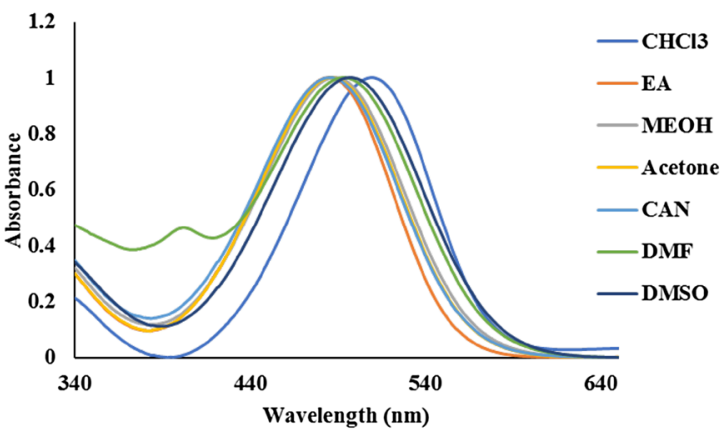

4

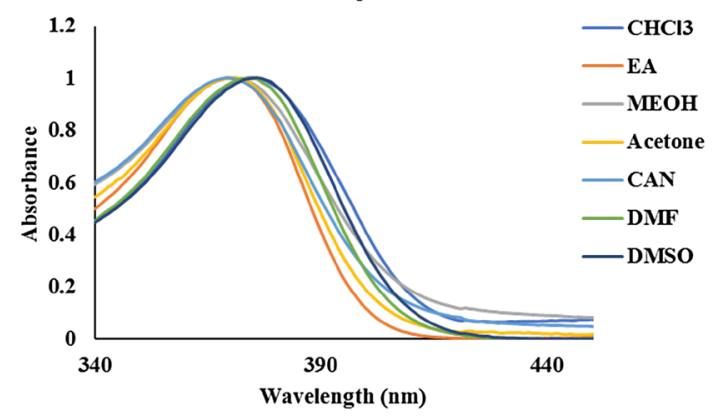

2

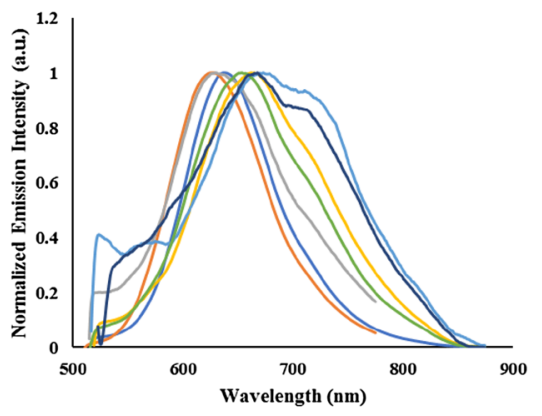

3

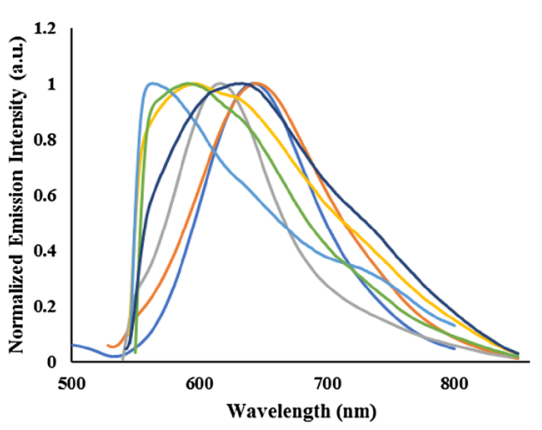

$-\mathrm{CHCl3}$

$-\mathbf{E A}$

MEOH

Acetone

- CAN

-DMF

-DMSO

Fig. 1 Normalized absorption and emission spectra of all four compounds in seven different solvents 
having electron withdrawing group $\mathrm{p}$-amino-salicylic acid (4) shows the least molar extinction coefficient (Table 1).

The molar extinction coefficient increases in the order: $\mathbf{4}<\mathbf{3}<\mathbf{2}<\mathbf{1}$ showing that the carboxycyano vinylene accepting group increases ICT in compound $\mathbf{1}$. A shoulder peak appearing at around $370 \mathrm{~nm}$ in the absorption spectra of compound $\mathbf{2}$ is due to the presence of rhodamine-3-acetic acid acceptor group. The absorption $\lambda_{\max }$ increases in the order: $\mathbf{4}<\mathbf{3}=\mathbf{1}<\mathbf{2}$ in acetonitrile. The compound $\mathbf{2}$ is the reddest shifted which is due to the acceptor, rhodamine3 -acetic acid which has more $\pi$-conjugation as compared to the other chromophores. A similar trend was observed in the Stokes shifts (Table 1). In the emission spectra, the same trend was observed, a red shift in emission $\lambda_{\max }$ was observed from compound 4 to 2 (500 to $673 \mathrm{~nm}$ ). So, it can be predicted that there is a better intramolecular charge transfer (ICT) after varying withdrawing groups from moderate to strong electron withdrawing groups.

The photophysical properties of the four compound $\mathbf{1}$, $\mathbf{2}, \mathbf{3}$, and $\mathbf{4}$ in different solvents are evaluated and tabulated in Table 1 and Table S1. They show quenching of fluorescence in polar solvents causing a lowering of quantum yield and red shifted emissions. The compound 1 shows the highest values of molar extinction coefficient, FWHM, Stokes shift, oscillator strength and transition dipole moment compared the other three compounds, while compound $\mathbf{4}$ shows the highest values of quantum yield, fluorescence lifetime and minimum non-radiative decay constant. The compound $\mathbf{1}$, and $\mathbf{4}$ show a lower value of non-radiative decay constant (Knr) than the other compound 2, and $\mathbf{3}$. All the compounds 1, 2, 3, and $\mathbf{4}$ show lower values of the non-radiative decay constant (Knr) than their corresponding radiative decay constant $(\mathrm{Kr})$ in all the solvents (Table S1). In polar solvents, the value of Knr increases for compounds 1, 2, and $\mathbf{4}$ (except compound 3).

\subsection{Solvatochromism}

The D- $\pi-A$ compounds show good solvatochromic behaviour. In D- $\pi-A$ chromophores the solvent polarity affects the excited state by stabilizing it through dipole-dipole interactions, and hydrogen bonding. Hence, we have studied the solvent dependent absorption and emission spectrum of these compounds in different solvents. We observed that the compound showed a red shift in absorption $(67 \mathrm{~nm})$ and a large red shift in emission $(69 \mathrm{~nm})$. These results are supported with the positive difference in dipole moment of the $S_{0}$ and $S_{1}$ state and increased Stokes shift in polar solvents as compared to the non-polar solvents (Table 1). The normalized emission spectra of the compounds 1, 2, 3, and $\mathbf{4}$ are shown in Fig. 1 which indicates the highest red shift in emission spectra $(69 \mathrm{~nm})$ of compound 1. The increase in Stokes shift with an increase in the solvent polarity in these compounds can be correlated by using Lippert-Mataga (LM) equation [62].

Figure 2 shows a linear relationship suggesting that solvent parameters such as dielectric constant and refractive index are responsible for the red shifted emission in compound $\mathbf{2}$. These compound 1, 2, 3, and $\mathbf{4}$ show different types of interactions with polar and non-polar solvents. Mac Rae (McR) model is the upgraded version of LM model where solute polarizability in addition to the solvent polarizability was taken into account [63]. We plotted the McR function $\left(\Delta f_{M R}\right)$ vs Stokes shift for the compound 1, 2, 3, and $\mathbf{4}$ as shown in Figure $\mathrm{S} 1$ and there exists a linear relationship suggesting that the polarity originating from the dipole created by this compound $\mathbf{1}, \mathbf{2}, \mathbf{3}$, and $\mathbf{4}$ and it also responsible for the solvatochromic shift in polar solvents. A similar molecular microscopic solvent polarity function $\left(E_{T}^{N}\right)$ by Reichardt $[64,65]$ which correlates much better with the solvatochromic shift of dipolar molecules rather than the traditionally used LM polarity functions is also plotted with the Stokes shift and linear relationship is observed as shown in Figure S2.

\subsection{Intramolecular charge transfer (ICT) and dipole moment}

ICT occurs upon excitation in $D-\pi-A$ chromophores, and this process becomes solvent dependent. Large Stokes shift (71 to $185 \mathrm{~nm}$ ) observed for this compound 1, 2, 3, and $\mathbf{4}$ suggests enough structural reorganization or a polar $S_{1}$ state as compared to $S_{0}$ state. The difference in dipole moment $(\mu)$ between the $S_{0}$ and $S_{1}$ state was calculated to understand the polarity of the excited state using $L M$, and McR functions. Table 2 gives the transition dipole moment $\left(\mu_{\text {eg }}\right)$, difference in dipole moments $\left(\Delta \mu_{\mathrm{eg}}\right)$ by experimental and DFT method and the ratio $\mu_{\mathrm{e}} / \mu_{\mathrm{g}}$ using Bilot-Kawaski (BK), Bakhshiev and Liptay correlations. Transition dipole moment $\left(\mu_{\mathrm{eg}}\right)$ is a measure of the probability of radiative transitions from $\mathrm{S}_{0}$ to $\mathrm{S}_{1}$ state and corelates with the oscillator strength. The positive values obtained for the difference in dipole moment $\left(\mu_{e}>\mu_{g}\right)$, and ratio of dipole moment $(\mu \mathrm{e} / \mu \mathrm{g})$ by experimental as well as DFT, confirmed that the $S_{1}$ state is polar than $S_{0}$. The compound 4 shows the highest values of $\Delta \mu_{\text {eg }}$ obtained by three different correlations (i.e. $L M, M c R$, and $B K$ ), while compound 1 shows the higher values of $\mu_{\mathrm{e}} / \mu_{\mathrm{g}}$ obtained by the other three different correlations (i.e. Bilot-Kawaski, Bakhshiev and Liptay).

\subsection{Viscosity study}

We studied the viscosity sensitivity $(\mathrm{x})$ of the TPA based chromophores in ethanol: PEG-400 mixture. The presence 

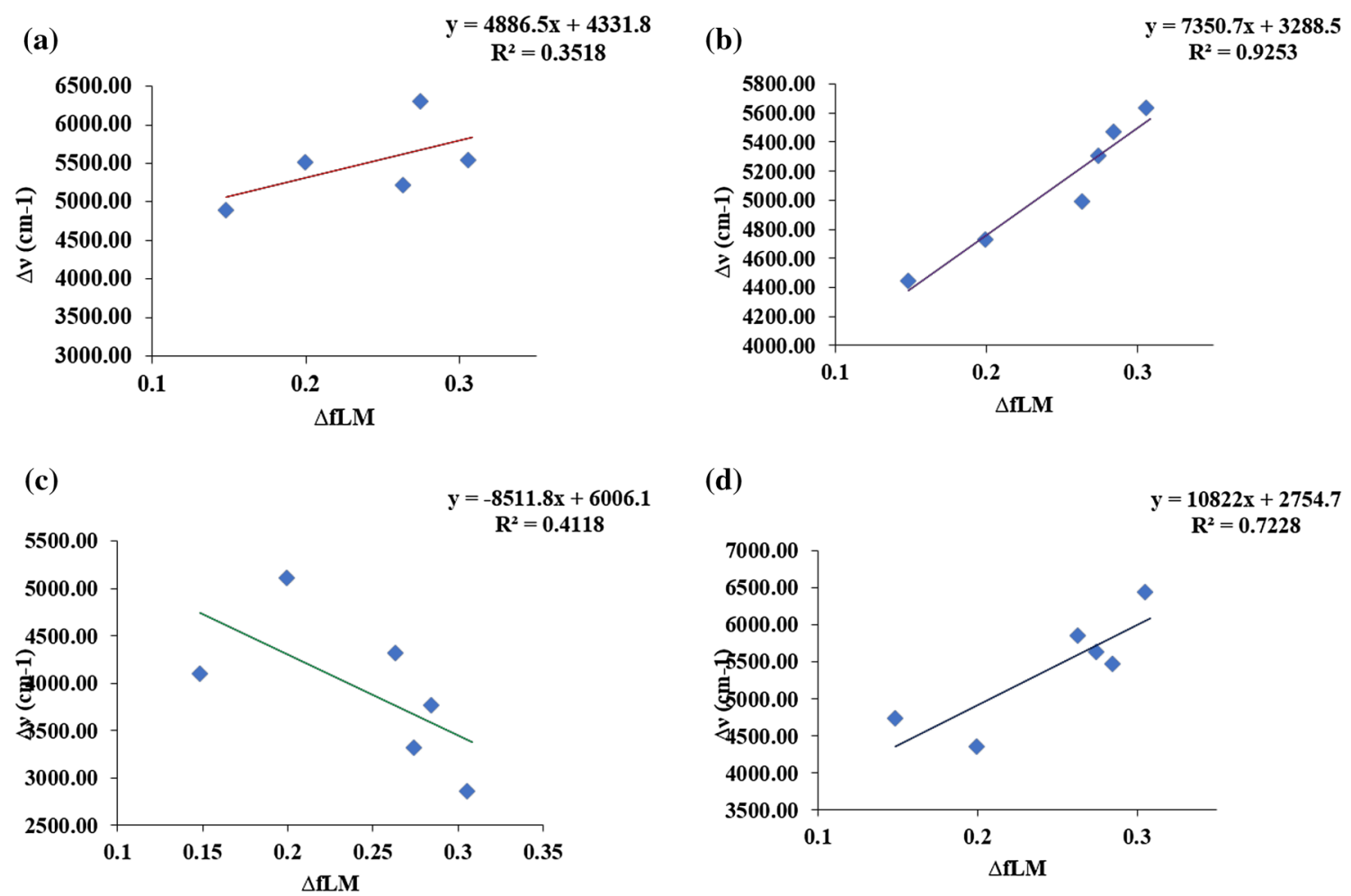

Fig. 2 Lippert-Mataga plots for compounds (a) 1, (b) 2, (c) 3, (d) 4 in different solvents

Table 2 Difference and ratio of dipole moment between ground and excited state of compound 1, 2, 3, and $\mathbf{4}$ by experimental as well as DFT method

\begin{tabular}{|c|c|c|c|c|c|c|c|c|}
\hline \multirow[t]{2}{*}{ Dye } & \multirow{2}{*}{$\begin{array}{l}\mu_{\mathrm{eg}} \\
\text { (Debye) }\end{array}$} & \multicolumn{3}{|c|}{$\Delta \mu_{\text {eg }}$ (Debye) } & \multirow{2}{*}{$\begin{array}{l}\mu \text { (DFT) } \\
\text { (Debye) }\end{array}$} & \multicolumn{3}{|c|}{$\mu_{\mathrm{e}} / \mu_{\mathrm{g}}$ (Debye) } \\
\hline & & LM & $M c R$ & BK & & BK & Bakhshiev & Liptay \\
\hline 1 & 22.17 & 9.41 & 5.36 & 14.98 & 1.41 & 14.58 & 14.30 & 15.81 \\
\hline 2 & 17.91 & 13.10 & 7.52 & 11.50 & 1.52 & 10.97 & 15.21 & 18.01 \\
\hline 3 & 14.99 & 12.72 & 7.50 & 4.37 & 2.47 & 9.88 & 14.26 & 18.75 \\
\hline 4 & 8.94 & 15.71 & 9.44 & 16.49 & 1.39 & 8.65 & 10.67 & 11.24 \\
\hline
\end{tabular}

of extra phenyl ring in TPA rotates around a single bond. TPA based compounds are known to show enhancement of fluorescence after hindering the rotation in viscous media [47]. A decrease in fluorescence intensity was observed in compound $\mathbf{1}, \mathbf{2}, \mathbf{3}$, and $\mathbf{4}$ as the polarity of solvent increases and these emissions are due to the TICT state formed in polar solvents. We used PEG-400 as a viscous solvent for viscosity studies. In $5 \mu \mathrm{M}$ solutions of the chromophores in ethanol, when the percentage of PEG was increased from 0 to $99 \%$ enhancement of fluorescence was observed with the increased percentage of PEG-400. Figure 3 represents viscosity induced emission of the chromophores with increasing percentage of PEG 400 in ethanol.

As seen from Fig. 3, a minimum 2.67 times and a maximum 14.14 times enhancement of fluorescence intensity respectively for compound $\mathbf{3}$ and $\mathbf{4}$ is observed. It is almost three to four times for compound $\mathbf{2}$ and $\mathbf{1}$ (8.64 and 9.81 respectively). The compound 4 shows 14.14 times fluorescence enhancement. The very high fluorescence enhancement observed for compound $\mathbf{4}$ is due to the formation of TICT state in the excited state which gets blocked in viscous media and show increased fluorescence with slightly blue shifted emission spectra. Between compound $\mathbf{1}$ and 2, comparatively better enhancement in fluorescence was observed for compound $\mathbf{1}$, which is coplanar with the $\pi$-bridge. Due to the good sensitivity of compound $\mathbf{4}$ to viscosity, it can be considered as a fluorescent molecular rotor (FMR) as it has emission wavelength, $465 \mathrm{~nm}$. The compound $\mathbf{1}$ and $\mathbf{2}$ are also good candidates for the FMRs as they show longer emission wavelengths (631 and $673 \mathrm{~nm}$ ) as compared to well-known FMR DCVJ. All the compound 1, 2, and $\mathbf{3}$ except compound $\mathbf{4}$ emitted above $600 \mathrm{~nm}$ which is due to the presence of strong withdrawing group, and they can be considered as good FMRs in the red to the deep red region for biological applications. 

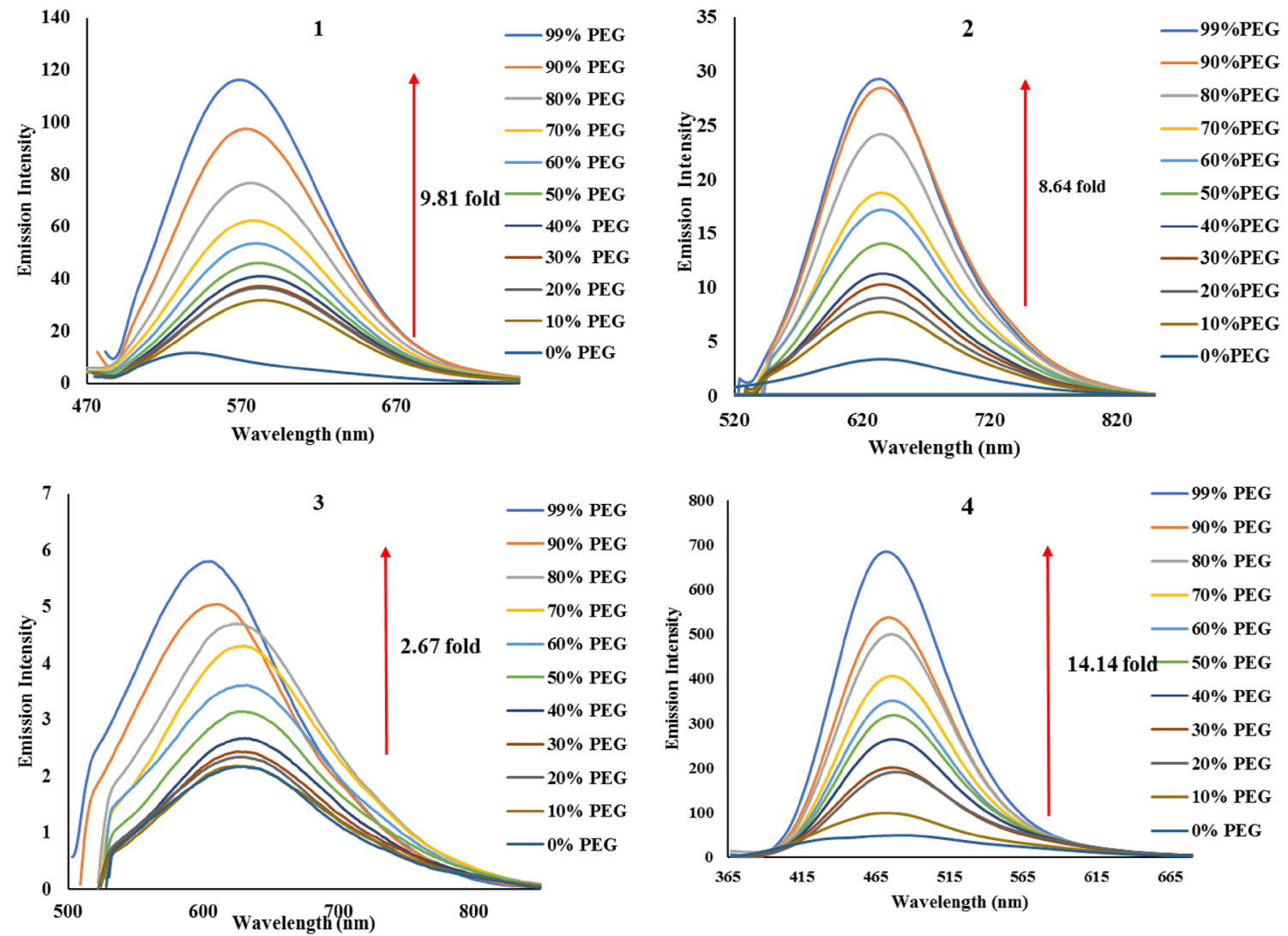

Fig. 3 Viscosity study of all four compounds in 0\% PEG to 99\% PEG

Similarly, compound $\mathbf{4}, \mathbf{2}$ and $\mathbf{3}$ show high Stokes shifts, 129,159 and $185 \mathrm{~nm}$ respectively compared to DCVJ. The compound $\mathbf{4}$ show high value of viscosity sensitivity $(x)$ 0.58 as compared to another compound 1, 2, and 3 (Figure S3).

\subsection{Multiple linear regression analysis}

Multiple linear regression analysis provides the information on different types of interactions between solute and solvent. It is also used to explain the mechanism of electronic transition. From the existing literature, it is well known that the intensity, position and shape of the excitation spectrum can explain the spectral shifts with the nature of solvent and solute. The spectral shifts induced by solvents were calculated using Kamlet-Taft parameters $\alpha, \beta$, and $\pi^{*}$. In order to get more information on the solvatochromic properties of dyes, the spectral properties are correlated with Kamlet-Taft parameters. The wave numbers of absorption $\left(v_{\mathrm{abs}}\right)$, fluorescence $\left(v_{\mathrm{em}}\right)$ and Stokes shift $\left(\Delta v_{\mathrm{St}}\right)$ are correlated with as $\alpha, \beta$, and $\pi^{*}$ using multiple linear regression analysis. This analysis is used to explain the mechanism of transitions between ground and excited states based on the information of

solute-solvent interactions. The solvatochromic parameters $\alpha, \beta$, and $\pi^{*}$ are summarized in Table 3 .

$v=v_{0}+a \alpha+b \beta+c \pi^{*}$

where $v$ represents the property to be correlated, $v_{0}$ stands for the property related to a standard process, a is the hydrogen bond donor acidity, $\beta$ is the hydrogen bond acceptor basicity, $\pi^{*}$ is the dipolarity-polarizability, while $a, b$ and $c$ are coefficients characteristic of a given compound.

Moreover, the new four-parameter Catalan solvent scale, which considers polarizability, dipolarity, acidity and basicity of a solvent, is also applied. It is shown that this new four-parameter Catalan solvent scale gives a better fit than the three-parameter scales.

$v=v_{0}+a_{S A} S A+b_{S B} S B+c_{S P P} S P P+d_{S P} S P$

SPP, SP, SA and SB characterize the dipolarity, polarizability, acidity, and basicity respectively.

The values of Kamlet-Taft parameters ( $\alpha, \beta$, and $\left.\pi^{*}\right)$ are tabulated in Table 3.

The analysis of emission data according to Kamlet-Taft Eq. 1 using a solvent scale in which solvent (di)polarity and polarizability effects are combined in the single parameter 
Table 3 Estimated coefficients $\left(y_{0}, a, b, c, d\right)$, their standard errors and correlation coefficients $(r)$ for the multi-linear analysis of $\left(\bar{v}_{\text {emi }}\right)$ of the compound 1, 2, $\mathbf{3}$ and $\mathbf{4}$ as a function of Kamlet-Taft solvent scales

\begin{tabular}{lllllll}
\hline Kamlet & $\bar{v}_{\text {emi }}$ & $\mathrm{Aa}$ & $\mathrm{b} \beta$ & $\mathrm{c} \pi^{*}$ & $\mathrm{r}$ \\
\hline 1 & $18.76 \pm 0.74$ & $(-2.41) \pm 0.67$ & $(-0.64) \pm 1.19$ & $(-2.74) \pm 0.51$ & 0.75 & 10 \\
2 & $16.29 \pm 1.13$ & $(-0.18) \pm 0.12$ & $(-0.32) \pm 1.83$ & $(-1.28) \pm 0.31$ & 0.62 & 10 \\
3 & $15.78 \pm 1.07$ & $(-0.16) \pm 0.97$ & $(-0.66) \pm 1.74$ & $(-1.36) \pm 0.19$ & 0.66 & 10 \\
4 & $17.30 \pm 0.89$ & $(-0.11) \pm 0.79$ & $(-0.75) \pm 1.43$ & $(-1.92) \pm 0.81$ & 0.71 & 10 \\
\hline
\end{tabular}

shows a poor-fit, as assessed by the value of $r(0.66)$ and the large standard errors on the estimated parameters aa, $\mathrm{b} \beta$, and $\mathrm{c} \pi^{*}$ as a quality-of-fit criterion. Conversely, use of Catalan solvent parameters, where (di) polarity and polarizability effects split, gives a perfect multi-linear fit to $v_{\text {emi }}$ $(r=0.82)$. Because this multiple linear regression gives relatively small estimates for aSA and bSB with comparatively large associated standard errors. We decided to perform the multi-linear analysis according to (Eq. 2) with solvent dipolarity (SPP) and polarizability (SP) as only solvent scales. This analysis gives better results $(r=0.82)$.

Multi-linear analysis is carried out in different solvents using emission data represented in Table 3. In the case of emission spectra again Catalan parameters show better correlation coefficient $(r=0.82)$ than Kamlet-Taft parameters (0.75). The negative value observed for all three solvent parameters (acidity, dipolarity and polarizability) both by Kamlet-Taft and Catalan analysis supports the red shifted emissions observed in polar solvents. Estimated coefficients for dyes by Kamlet-Taft and Catalan method are represented in Tables 3 and 4. By seeing the sign of each estimated coefficient as well as the extent of standard error and correlation coefficient obtained by both the methods, solvent dipolarity emerges out as the main factor responsible for the shift in absorption as well as in emission. Hence solvent dipolarity can be considered as the main factor responsible for the slightly red shifted absorption as well as highly red shifted emission spectra of all the dyes.

\subsection{Theoretical investigation}

\subsubsection{Optimized geometries}

Geometry optimizations of the compound 1, 2, 3, and 4 in gas phase as well as in solvents are carried out using time-dependent density functional theory (TD-DFT) calculations with the Gaussian 09 program using the popular global hybrid functional, B3LYP [66-68]. The optimized geometries of all chromophore are displayed in Figure S4. One phenyl ring in TPA is always twisted. The frontier molecular orbital (FMO) of all chromophore are displayed in Fig. 4. The electron density is uniformly distributed over the dye, D unit, $\pi$-linker and $A$ unit. In HOMO, the electron density is located on the donor group (TPA) and $\pi$-linker, and in the LUMO electron density is located on the withdrawing unit and $\pi$-linker. The minimum overlap of electron density between HOMO and LUMO is observed in the case of compound $\mathbf{1}$ and $\mathbf{3}$ as compared with compound $\mathbf{2}$ and $\mathbf{4}$ showing that the more effective charge transfer is possible in the presence of strong withdrawing groups. MEP diagram supports the FMO diagram of all the chromophores (Figure S5).

The energy gap between HOMO and LUMO for the compound 1, 2, 3, and $\mathbf{4}$ are calculated in chloroform and are represented in Figure $\mathbf{S 6}$. As expected, compound 3 shows the lowest energy difference between HOMO and LUMO (2.51 eV) which is due to the strong withdrawing unit present in this compound. The compound $\mathbf{4}$ shows the highest difference between HOMO and LUMO $(2.91 \mathrm{eV})$ due to the presence of weak withdrawing unit, 4-aminosalyclic acid. The computationally obtained lowest energy transitions i.e. vertical excitations, oscillator strengths and dipole moments in chloroform are compared with the experimentally observed absorptions, oscillator strength and dipole moment derived from absorption $\lambda_{\max }$ in chloroform solvent (Table 5). In general, computationally obtained vertical excitation values are well in agreement with the experimental value. A similar trend for the experimentally and computationally observed oscillator strengths
Table 4 The correlation coefficients ( $r$ ) for the multilinear analysis of $\left(\bar{v}_{\text {emi }}\right)$ of compounds 1, 2, 3 and $\mathbf{4}$ as a function of Catalan solvent scales

\section{SN Applied Sciences}

\begin{tabular}{llllllll}
\hline Catalan & $\bar{v}_{\text {emi }}$ & aSA & bSB & cSPP & dSP & $r$ & $n$ \\
\hline 1 & $19.39 \pm 2.54$ & $(-2.47) \pm 1.34$ & $(-0.45) \pm 1.15$ & $(-3.27) \pm 1.02$ & $(-2.32) \pm 1.27$ & 0.82 & 10 \\
2 & $17.08 \pm 3.68$ & $(-1.49) \pm 1.14$ & $(-0.26) \pm 1.60$ & $(-2.64) \pm 1.47$ & $(-2.45) \pm 1.75$ & 0.72 & 10 \\
3 & $18.61 \pm 2.68$ & $(-1.55) \pm 1.41$ & $(-0.02) \pm 1.17$ & $(-2.85) \pm 1.07$ & $(-2.32) \pm 1.46$ & 0.78 & 10 \\
4 & $16.52 \pm 2.29$ & $(-1.25) \pm 1.21$ & $(-0.58) \pm 1.99$ & $(-2.45) \pm 0.92$ & $(-2.71) \pm 1.95$ & 0.75 & 10 \\
\hline
\end{tabular}




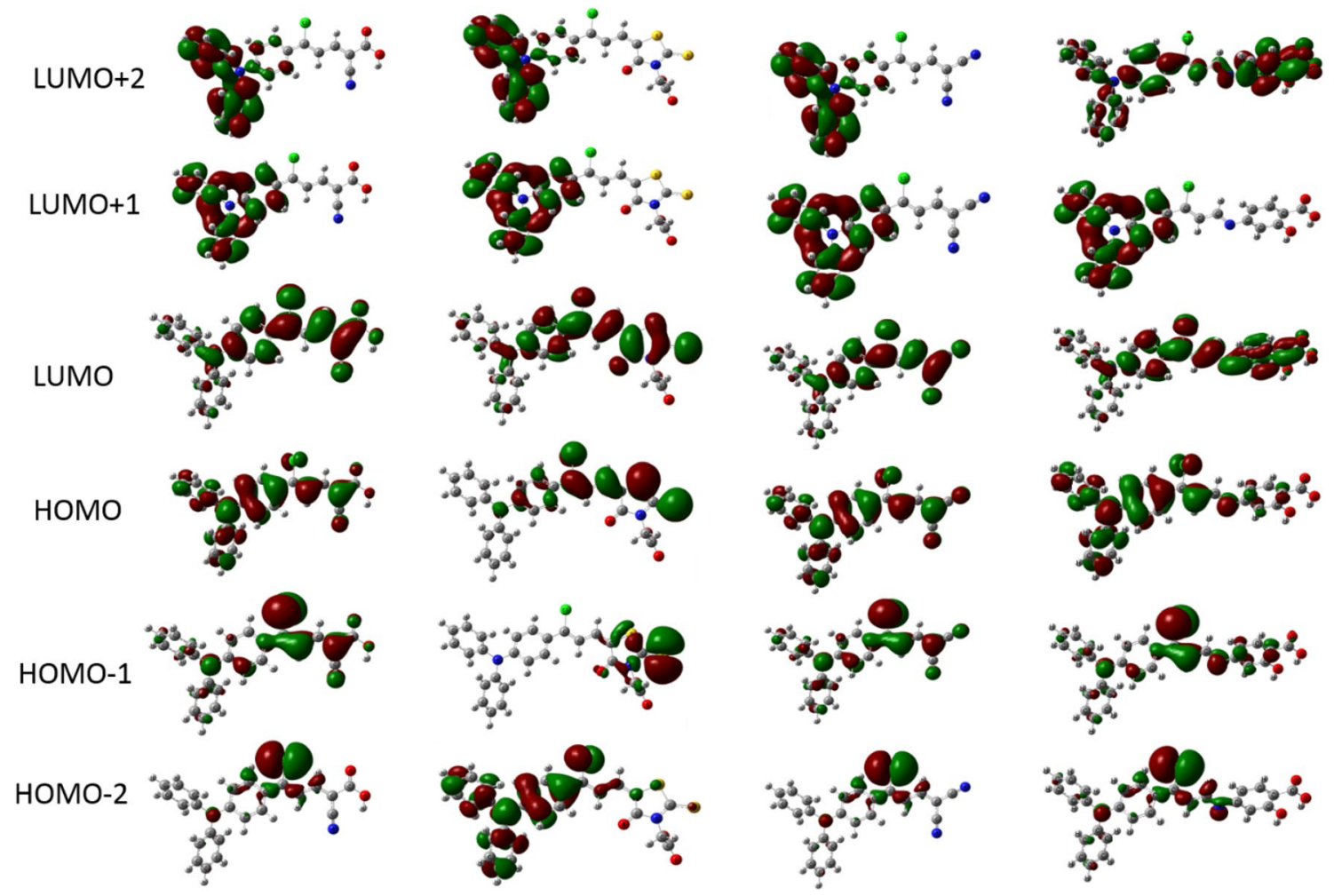

Fig. 4 Frontier molecular orbital (FMO) of compounds 1, 2, 3, and 4 from left to right

is found, and the only exception is of compound $\mathbf{1}$ which shows almost double the value of experimental oscillator strength compared to the computational value. Though the experimentally calculated dipole moment increases in the order $\mathbf{4}<\mathbf{3}<\mathbf{2}<\mathbf{1}$, computational dipole moment increases in the order $\mathbf{2}<\mathbf{1}<\mathbf{4}<\mathbf{3}$.

\subsubsection{NBO study}

The charge distribution and electron transfer in $\mathrm{D}-\pi-\mathrm{A}$ compound 1, 2, 3, and $\mathbf{4}$ are understood by the natural bond orbital (NBO) analysis. The charges on the atoms in the ground state give some idea about the electron delocalization inside the chromophore. The natural charges on selected atoms inside the chromophores in chloroform are tabulated in Table 6. It was observed that the negative charge on nitrogen atom $\left(\mathrm{N}_{12}\right)$ increased in the order: $\mathbf{1}<\mathbf{3}<\mathbf{2}<\mathbf{4}$ indicating that the lone pair of nitrogen atom migrates from $D$ to $A$. The $C_{41}$ carbon acts as acceptor which has increased positive charge on carbonyl carbon. In case of compound $\mathbf{1}$ and $\mathbf{2} \mathrm{C}_{41}$ carbon shows more positive charge than the other two compound $\mathbf{3}$, and $\mathbf{4}$ which is due to the presence of the strong electron withdrawing group. In case of compound $\mathbf{2} C_{50}$ carbon atom shows more positive charge than $C_{41}$ because $C_{50}$ was the carbonyl carbon atom. In case of 1, 2, and $\mathbf{3}$ negative charge increased over $\mathrm{N}_{46}, \mathrm{~N}_{45}$ and $\mathrm{N}_{44}$ respectively showing that the electrons are delocalized towards the positive charge density.
Table 5 Selected properties of the compounds (experimental and computational) in chloroform

\begin{tabular}{|c|c|c|c|c|c|c|}
\hline \multirow[t]{2}{*}{ Chromophores } & \multicolumn{2}{|c|}{$\lambda_{\mathrm{abs}}(\mathrm{nm})$} & \multicolumn{2}{|l|}{$f$} & \multicolumn{2}{|c|}{$\mu_{\text {eg }}$ (Debye) } \\
\hline & $a$ & $b$ & $a$ & $b$ & $a$ & $b$ \\
\hline 1 & 482 & 546 & 4.68 & 2.27 & 22.17 & 12.64 \\
\hline 2 & 497 & 583 & 3.03 & 2.12 & 17.91 & 11.55 \\
\hline 3 & 509 & 542 & 2.07 & 2.28 & 14.99 & 14.28 \\
\hline 4 & 375 & 491 & 1.01 & 2.52 & 8.94 & 13.46 \\
\hline
\end{tabular}

a experimental value, ${ }^{b}$ computational value 
Table 6 Natural charges of theselected atom at ground state (GS) at B3LYP with 6-311++G(d,p) in $\mathrm{CHCl}_{3}$

\begin{tabular}{|c|c|c|c|c|c|c|c|}
\hline \multicolumn{2}{|l|}{1} & \multicolumn{2}{|l|}{2} & \multicolumn{2}{|l|}{3} & \multicolumn{2}{|l|}{4} \\
\hline Atom no. & $\mathrm{NC}$ & Atom no. & $\mathrm{NC}$ & Atom no. & $\mathrm{NC}$ & Atom no. & NC \\
\hline $\mathrm{N}_{12}$ & -0.4773 & $\mathrm{~N}_{12}$ & -0.4891 & $\mathrm{~N}_{12}$ & -0.4795 & $\mathrm{~N}_{12}$ & -0.4950 \\
\hline$C_{1}$ & 0.2235 & $C_{1}$ & 0.2080 & $C_{1}$ & 0.2226 & $C_{1}$ & 0.2027 \\
\hline$C_{2}$ & -0.2650 & $C_{2}$ & -0.2615 & $C_{2}$ & -0.2639 & $\mathrm{C}_{2}$ & -0.2336 \\
\hline$C_{3}$ & -0.0779 & $C_{3}$ & -0.0891 & $C_{3}$ & -0.0780 & $C_{3}$ & -0.1526 \\
\hline $\mathrm{C}_{4}$ & -0.2075 & $C_{4}$ & -0.1758 & $\mathrm{C}_{4}$ & -0.1867 & $\mathrm{C}_{4}$ & -0.1749 \\
\hline$C_{11}$ & 0.0882 & $C_{11}$ & 0.0595 & $C_{11}$ & 0.0840 & $C_{11}$ & 0.0486 \\
\hline$C_{13}$ & -0.3082 & $C_{13}$ & -0.2903 & $C_{13}$ & -0.3062 & $C_{13}$ & -0.2814 \\
\hline $\mathrm{Cl}_{37}$ & 0.0194 & $\mathrm{Cl}_{37}$ & -0.0029 & $\mathrm{Cl}_{37}$ & 0.0187 & $\mathrm{Cl}_{37}$ & -0.0035 \\
\hline$C_{38}$ & -0.0422 & $C_{38}$ & -0.1203 & $C_{38}$ & -0.0453 & $C_{38}$ & 0.1208 \\
\hline$C_{40}$ & -0.3339 & $C_{40}$ & -0.2926 & $C_{40}$ & -0.3232 & $\mathrm{C}_{40}$ & -0.4709 \\
\hline$C_{41}$ & 0.7982 & $C_{41}$ & 0.6649 & $C_{41}$ & 0.3093 & $C_{41}$ & 0.1769 \\
\hline $\mathrm{O}_{42}$ & -0.6810 & $C_{43}$ & -0.1027 & $\mathrm{~N}_{42}$ & -0.3530 & $C_{42}$ & -0.2763 \\
\hline $\mathrm{O}_{44}$ & -0.6310 & $\mathrm{~S}_{44}$ & -0.1067 & $C_{43}$ & 0.3147 & $C_{44}$ & 0.3513 \\
\hline$C_{45}$ & 0.2828 & $\mathrm{~N}_{45}$ & -0.4985 & $\mathrm{~N}_{44}$ & -0.3579 & $C_{48}$ & -0.2379 \\
\hline \multirow[t]{2}{*}{$\mathrm{N}_{46}$} & -0.3770 & $\mathrm{C}_{49}$ & 0.8131 & & & $C_{50}$ & 0.7944 \\
\hline & & $\mathrm{O}_{53}$ & -0.6096 & & & $\mathrm{O}_{53}$ & -0.6966 \\
\hline
\end{tabular}

\subsubsection{Electronic transitions}

The calculated electronic vertical transition energy, oscillator strengths $(f)$, maximum absorption wavelength $\left(\lambda_{\max }\right)$ and nature of the transitions are collected in Table 7 . The electronic transition could be influenced by the polarity of solvents. From Table 7, the strongest absorption value for all sensitizers are mainly related to the transition from the HOMO to the LUMO. Major contributions of electronic transitions were observed $98-99 \%$ from $\mathrm{HOMO}$ to LUMO. Moreover, one can find that the TD-DFT calculated maximum vertical excitation of compound $\mathbf{2}$ was remarkably red-shifted in all solvents as compared to other TPA chromophores and the increasing order is: $\mathbf{4}<\mathbf{3}<\mathbf{1}<\mathbf{2}$ (as obtained from both DFT functional). Similar trends were observed in the experimental and computational methods using the functional CAM-B3LYP and B3LYP. Computationally compound $\mathbf{2}$ shows vertical excitation at a longer wavelength than the other compound 1, 3, and $\mathbf{4}$. The trend in experimental absorption is similar.

\subsubsection{BLA and BOA study}

Bond length alteration (BLA) and bond order alteration (BOA) are the geometrical and electronical parameters that depend on the $\pi$-conjugation length and the strength of the $D$ and $A$ units. The BLA and BOA values of ground state optimized geometries were calculated using the B3LYP optimized geometries. BLA and BOA values are shown in Table 8 . From Table 8 it is seen that the BLA values increase in the order $\mathbf{3}<\mathbf{4}<\mathbf{2}<\mathbf{1}$ whereas BOA value shows the reverse trend. The magnitudes of $\mu, a$, and $\beta$ increases with increasing donor to acceptor strength and increasing $\pi$-conjugation length, especially in case of compound 1.
Table 7 Electronic transition data obtained by TD-B3LYP and CAM-B3LYP/6-

$311++G(d, p)$ level of each molecule in $\mathrm{CHCl}_{3}$ solution

\begin{tabular}{lllllll}
\hline Dyes & functional & $\lambda_{\max }(\mathrm{nm})$ & States & $f$ & $\begin{array}{l}\text { Excited } \\
\text { energy }(\mathrm{eV})\end{array}$ & Transition character \\
\hline 1 & & & & & 2.27 & $104 \rightarrow 105(99.82 \%)$ \\
& B3LYP & 546 & $\mathrm{~S} 1$ & 1.156 & 2.71 & $104 \rightarrow 105(89.95 \%)$ \\
2 & CAM-B3LYP & 457 & $\mathrm{~S} 1$ & 1.425 & 2.12 & $131 \rightarrow 132(99.71 \%)$ \\
3 & B3LYP & 583 & $\mathrm{~S} 1$ & 1.208 & $131 \rightarrow 132(85.76 \%)$ \\
& CAM-B3LYP & 475 & $\mathrm{~S} 1$ & 1.575 & 2.61 & $131 \rightarrow 100(99.72 \%)$ \\
4 & B3LYP & 542 & $\mathrm{~S} 1$ & 1.135 & 2.28 & $90 \rightarrow 100(90.25 \%)$ \\
& CAM-B3LYP & 456 & $\mathrm{~S} 1$ & 1.434 & 2.71 & $90 \rightarrow 100)$ \\
& B3LYP & 491 & $\mathrm{~S} 1$ & 1.182 & 2.52 & $122 \rightarrow 123(98.75 \%)$ \\
& CAM-B3LYP & 394 & $\mathrm{~S} 1$ & 1.673 & 3.14 & $122 \rightarrow 123(80.41 \%)$ \\
\hline
\end{tabular}

$(104,131,90$ and 122 are HOMOs of compounds $\mathbf{1}, \mathbf{2}, \mathbf{3}$, and $\mathbf{4}$ respectively) 


\subsection{NLO study}

\subsubsection{Solvatochromic method for determination of NLO properties}

The values of the linear polarizability $a_{C T}$ of TPA based $D-\pi-A$ chromophores are obtained by using absorption and emission spectroscopy. The solvatochromic method is utilized for determination of dipole moment of the lowest lying CT excited state. The chromophores show good CT character in one direction is essentially coincident with the molecular long axis (X-axis) [69, 70]. The linear polarizability is sensitive to solvents and is evident in both the experimental and computational studies. The compound $\mathbf{2}$ and $\mathbf{3}$ show the higher $a_{C T}$ value in polar solvents. There is a substantial increase from 18 to $29 \times 10^{-24}$ esu to $122-202 \times 10^{-24}$ esu. The values forthe first hyperpolarizability obtained using the solvatochromic method (Table 9) are based on several assumptions and thus allow only an approximate estimate of the dominant tensor of total hyperpolarizability along the direction of CT which is the major contributor to the total hyperpolarizability. The solvatochromic $\beta_{C T}$ values are given in Table 9. The solvatochromic values of $\beta$ for all compound 1, 2, 3 and 4 though differ in their values, are in order of $\left(\times 10^{-30}\right)$ esu. The $\beta_{C T}$ values are higher in polar solvents such as methanol, DMF, and DMSO.

A comparison between B3LYP computed and experimental values shows that compound $\mathbf{2}$ has the computed values of $76\left(\times 10^{-30}\right)$ esu to $88\left(\times 10^{-30}\right)$ esu and experimental values from $163\left(\times 10^{-30}\right)$ esu to $271\left(\times 10^{-30}\right)$ esu

Table 8 BLA and BOA of all compounds obtained by B3LYP/6$311++G(d, p)$

\begin{tabular}{lrrrr}
\hline Sensitizer & \multicolumn{1}{l}{1} & \multicolumn{1}{l}{2} & 3 & \multicolumn{1}{l}{4} \\
\hline BLA & 0.09734 & 0.07172 & 0.06561 & 0.06922 \\
BOA & -0.54078 & -0.32598 & -0.29824 & -0.10201 \\
\hline
\end{tabular}

across the solvents. The value of $\beta_{0}$ or total first order hyperpolarizability of the molecule gives an estimate of the NLO properties of the organic molecules. This value considers all the directional tensor components of hyperpolarizability. The solvent effect is consistently shown higher in polar solvents (methanol, DMSO, and DMF) by the solvatochromic method.

The second-order hyperpolarizability at molecular level originating from the electronic polarization in the nonresonant region can be treated by a three-level model [71-75].

The second order hyperpolarizability can be expressed as the "solvatochromic descriptor" and the values calculated are given in Table 10. The solvent effect is also evident in this parameter, higher the polarity of the solvent (methanol), higher the second order hyperpolarizability. The compound $\mathbf{4}$ has solvatochromic values of $37\left(\times 10^{-36}\right)$ esu to $50\left(\times 10^{-30}\right)$ esu. The individual components of the second order static hyperpolarizability $\gamma$ are obtained computationally. The values are proportional to the solvatochromic descriptor $y$ of the second order hyperpolarizability. The values have a trend where higher polarity solvents show higher values of $\gamma$, and a similar trend is followed by the solvatochromic obtained values.

\subsubsection{NLO properties by using DFT and TD-DFT method}

The first and second order hyperpolarizability ( $\beta$ and $\gamma$ ), static polarizability $(\mathrm{a} 0)$, and related properties dipole $\operatorname{moment}(\mu), \Delta \mathrm{a}, \mathrm{av} \delta, \beta$, for all the chromophores are calculated using the B3LYP and CAM-B3LYP functionals with $6-311+G(d, p)$ basis set [76]. The values calculated of the TPA chromophores in different solvent environments using Eqs. (13-17) in supporting information are enlisted in Table 11 and Table S3. A comparison of the calculated hyperpolarizabilities suggests that the results obtained by using the B3LYP functional are better than those obtained CAM-B3LYP functional. B3LYP functional
Table 9 Effect of solvent on values of polarizabilities (a) (all values in $\times 10^{-24}$ esu), first hyperpolarizabilities $(\beta)$ (all values in $\times 10^{-30} \mathrm{esu}$ ) and static second hyperpolarizability $(\gamma)$ (all values in $\times 10^{-36} \mathrm{esu}$ ) for compounds $\mathbf{1}, \mathbf{2}, \mathbf{3}$, and $\mathbf{4}$

\begin{tabular}{|c|c|c|c|c|c|c|c|c|c|c|c|c|}
\hline \multirow[t]{2}{*}{ Solvents } & \multicolumn{3}{|l|}{1} & \multicolumn{3}{|l|}{2} & \multicolumn{3}{|l|}{3} & \multicolumn{3}{|l|}{4} \\
\hline & a & $\beta_{\mathrm{CT}}$ & $\gamma$ & $a$ & $\beta_{\mathrm{CT}}$ & $\gamma$ & a & $\beta_{\mathrm{CT}}$ & Y & a & $\beta_{\mathrm{CT}}$ & $\gamma$ \\
\hline $\mathrm{CHCl}_{3}$ & 164 & 344 & -1010 & 111 & 249 & -271 & 127 & 185 & -1067 & 20.8 & 39.4 & 45.6 \\
\hline EA & 165 & 345 & -946 & 118 & 261 & -339 & 163 & 242 & -1841 & 20.2 & 37.6 & 43.1 \\
\hline Acetone & 124 & 262 & -417 & 120 & 236 & -380 & 122 & 173 & -908 & 25.9 & 45.9 & 41.1 \\
\hline ACN & 168 & 354 & -991 & 117 & 260 & -340 & 124 & 163 & -906 & 24.7 & 46.1 & 48.2 \\
\hline $\mathrm{MeOH}$ & 173 & 371 & -1091 & 93.9 & 195 & -173 & 154 & 221 & -1581 & 29.7 & 55.2 & 49.6 \\
\hline DMF & 121 & 220 & -415 & 124 & 278 & -400 & 202 & 271 & -2716 & 20.2 & 38.3 & 45.2 \\
\hline DMSO & 139 & 292 & -607 & 131 & 289 & -520 & 162 & 234 & -1789 & 18.3 & 32.9 & 36.9 \\
\hline
\end{tabular}


Table 10 Comparison between solvatochromic and theoretical NLO value of compounds 1, 2, $\mathbf{3}$, and $\mathbf{4}$ in chloroform

\begin{tabular}{|c|c|c|c|c|c|c|c|c|c|}
\hline \multirow[t]{2}{*}{ Dyes } & \multicolumn{4}{|c|}{ Experimental } & \multicolumn{5}{|c|}{ Computational } \\
\hline & $\mu$ & $a$ & $\beta$ & $\gamma$ & $\mu$ & 0 & $\Delta$ & $\beta$ & $\gamma$ \\
\hline & & $10^{-24}$ & $10^{-30}$ & $10^{-36}$ & & $10^{-24}$ & $10^{-24}$ & $10^{-30}$ & $10^{-36}$ \\
\hline 1 & 22 & 164 & 133 & -1010 & 10 & 109 & 26481 & 845 & 4108 \\
\hline 2 & 17 & 111 & 249 & -271 & 11 & 107 & 24361 & 772 & 3918 \\
\hline 3 & 15 & 127 & 185 & -1067 & 15 & 84 & 14292 & 605 & 1827 \\
\hline 4 & 9 & 20.8 & 39.4 & 45.6 & 14 & 91 & 15727 & 517 & 2995 \\
\hline
\end{tabular}

Static dipole moment $\left[\mu\right.$ (Debye)], mean polarizability $\left[a_{0}\left(10^{-24}\right.\right.$ esu) $],^{c}$ polarizability anisotropy $[\Delta a$ $\left.\left(10^{-24} \mathrm{esu}\right)\right]$, first hyperpolarizability $\left[\beta_{0}\left(10^{-30} \mathrm{esu}\right)\right]$, second hyperpolarizability $\left[\gamma\left(10^{-36} \mathrm{esu}\right)\right]$
Table 11 Theoretical NLO value of compounds 1, 2, 3, and 4 in chloroform

\begin{tabular}{lcrrll}
\hline Dyes & $\mu$ & $\begin{array}{l}a_{0} \\
10^{-24}\end{array}$ & $\begin{array}{l}\Delta a \\
10^{-24}\end{array}$ & \multicolumn{1}{l}{$\begin{array}{l}\beta \\
10^{-30}\end{array}$} & $\begin{array}{l}Y \\
10^{-36}\end{array}$ \\
\hline 1 & & & & & \\
B3LYP & 10 & 109 & 26481 & 845 & 4108 \\
CAM- B3LYP & 13 & 76 & 8504 & 416 & 1253 \\
2 & & & & & \\
B3LYP & 11 & 107 & 24361 & 772 & 3918 \\
CAM-B3LYP & 10 & 94 & 14586 & 414 & 2008 \\
3 & 15 & 84 & 14292 & 605 & 1827 \\
B3LYP & 14 & 76 & 9122 & 417 & 1313 \\
CAM-B3LYP & & & & & \\
4 & 14 & 91 & 15727 & 517 & 2995 \\
B3LYP & 13 & 82 & 9507 & 250 & 1209 \\
CAM-B3LYP & 15 & & & \\
\hline
\end{tabular}

Static dipole moment $\left[\mu\right.$ (Debye)], mean polarizability $\left[a_{0}\left(10^{-24}\right.\right.$ esu)], ' polarizability anisotropy $\left[\Delta a\left(10^{-24}\right.\right.$ esu)], first hyperpolarizability $\left[\beta_{0}\left(10^{-30} \mathrm{esu}\right)\right]$, second hyperpolarizability $\left[\gamma\left(10^{-36} \mathrm{esu}\right)\right]$

predicts higher $\beta$ values as compared to the CAM-B3LYP functional.

\subsubsection{Vibrational contribution to the linear and NLO response}

The connection between an electronic polarization and the vibrational motions leads to a considerable vibrational input to the non-linear optical (NLO) properties. DFT is a current technique to calculate the vibrational input towards polarizability and hyperpolarizability of NLO materials. The vibrational contributions to electronic hyperpolarizabilities and polarizabilities were calculated by using B3LYP functionals and $6-311++G(d, p)$ basis set in ethanol. The vibrational input to an element of $a$ and $\beta$ tensor has been calculated and compared with the corresponding electronic counterpart and listed in Table S4. The results show that the power of an individual component indicates a significant delocalization of charges.

\subsubsection{Limits for the hyperpolarizability values}

The limits for NLO values are obtained by the limiting theory proposed by Kuzyk [77].The $\gamma$ values have two fundamental limits are negative limit a centrosymmetric and positive limit for an asymmetric NLO molecule. The limiting values for $\beta$ and $\gamma$ are compared with the corresponding obtained values by solvatochromic and theoretical calculations for compound 1, 2, 3, and $\mathbf{4}$ in Table S3. Table S3 shows that $\beta$ values below the $\beta_{\max }$ limit and $\gamma$ values are within the predictable limiting values for all chromophores in all solvents.

\section{Conclusion}

A triphenylamine based donor with chloro-group suitably placed on $\pi$-linker with different electron withdrawing groups. Rhodamine-3-acetic acid as an electron withdrawing group offers an increased length of $\pi$-conjugation in compound 2, and it showed red shifted absorptions as well as emissions as compared to other three chromophores. The compound $\mathbf{2}$ and $\mathbf{4}$ show good linearity with respective the $L M$ and $M c R$ polarity functions. The observed trends in LM and McR for compounds $\mathbf{1}$ to $\mathbf{4}$ are: $\mathbf{1}<\mathbf{3}<\mathbf{4}<\mathbf{2}$. The chromophores can be separated into two groups as ICT (2) and TICT (1, 2, and 4) depending viscosity sensitivity which is moderate (2.12) to very high (14.14) respectively. The compound $\mathbf{4}$ shows high viscosity sensitivity value $(x=0.57)$ as compared to the very famous FMR DCVJ have $x$ value 0.40 in same viscous media. The multilinear analysis of absorption and emission spectrais carried out by using Kamlet-Taft and Catalan parameters which shows that solvent dipolarityand polarizability are main factors responsible for the slightly red shifted absorption and emission. BLA values show a linear correlation with the computationally obtained NLO parameters. The NLO properties of all the chromophores are investigated experimentally and computationally. The compound $\mathbf{1}$ is a better NLO material than the other three compound 2, 
3, and 4. The compound $\mathbf{4}$ is a good FMR for viscosity sensitivity study.

Acknowledgements The authors, Dinesh Patil, Kiran Avhad and Mayuri Kadam are thankful to UGC-SAP, India for Junior and Senior Research Fellowships.

\section{Compliance with ethical standards}

Conflicts of interest The authors declare that they have no conflict of interest.

\section{References}

1. Krishna A, Varathan E, Sreedevi P, Subramanian V, Karunakaran V, Varma RL (2018) Design, synthesis and photophysical investigation of triphenylamine-bithiophene dyes as RGB emitters for white light applications. Dyes Pigm 159:77-84. https://doi. org/10.1016/j.dyepig.2018.06.001

2. Fang Z, Teo TL, Cai L, Lal YH, Samoc A, Samoc M (2009) Bridged triphenylamine-based dendrimers: tuning enhanced two-photon absorption performance with locked molecular planarity. Org Lett 11:1-4. https://doi.org/10.1021/ol801238n

3. Fang Z, Zhang X, Lai YH, Liu B (2009) Bridged triphenylamine based molecules with large two-photon absorption cross sections in organic and aqueous media. Chem Commun (Camb). https://doi.org/10.1039/b812649f

4. Bélières $M$, Sartor V, Fabre PL, Poteau R, Bordeau G, ChouiniLalanne N (2018) Simple electron donor molecules based on triphenylamine and carbazole derivatives. Dyes Pigm 153:275283. https://doi.org/10.1016/j.dyepig.2018.02.022

5. Wei P, Bi X, Wu Z, Xu Z (2005) Synthesis of triphenylaminecored dendritic two-photon absorbing chromophores. Org Lett 7:3199-3202. https://doi.org/10.1021/ol050905n

6. Hrobárik $\mathrm{P}$, Hrobáriková V, Sigmundová I, Zahradník P, Fakis M, Polyzos I, Persephonis P (2011) Benzothiazoles with tunable electron-withdrawing strength and reverse polarity: a route to triphenylamine-based chromophores with enhanced twophoton absorption. J Org Chem 76:8726-8736. https://doi. org/10.1021/jo201411t

7. Porrès $L$, Mongin $O$, Katan $C$, Charlot $M$, Pons T, Mertz J, Blanchard-Desce M (2004) Enhanced two-photon absorption with novel octupolar propeller-shaped fluorophores derived from triphenylamine. Org Lett 6:47-50. https://doi.org/10.1021/ol036 041s

8. Lartia R, Allain C, Bordeau G, Schmidt F, Fiorini-Debuisschert C, Charra F, Teulade-Fichou M-P (2008) Synthetic strategies to derivatizable triphenylamines displaying high two-photon absorption. J Org Chem 73:1732-1744. https://doi.org/10.1021/jo702 $002 y$

9. Xu B, Fang H, Chen F, Lu H, He J, Li Y, Chen Q, Sun H, Tian W (2009) Synthesis, characterization, two-photon absorption, and optical limiting properties of triphenylamine-based dendrimers. New J Chem 33:2457-2464. https://doi.org/10.1039/B9NJ00393B

10. Zeng S, Ouyang X, Zeng H, Ji W, Ge Z (2012) Synthesis, tunable two and three-photon absorption properties of triazine derivatives by branches. Dyes Pigm 94:290-295. https://doi. org/10.1016/j.dyepig.2012.01.014

11. Zhang X, Ren X, Xu Q-H, Loh KP, Chen Z-K (2009) One- and two-photon turn-on fluorescent probe for cysteine and homocysteine with large emission shift. Org Lett 11:1257-1260. https://doi.org/10.1021/ol802979n
12. Wu G, Kong F, Zhang Y, Zhang X, Li J, Chen W, Liu W, Ding Y, Zhang C, Zhang B, Yao J, Dai S (2014) Multiple-anchoring triphenylamine dyes for dye-sensitized solar cell application. J Phys Chem C 118:8756-8765. https://doi.org/10.1021/jp412 4265

13. Qin $P$, Zhu H, Edvinsson T, Boschloo G, Hagfeldt A, Sun L (2008) Design of an organic chromophore for p-type dye-sensitized solar cells. J Am Chem Soc 130:8570-8571. https://doi. org/10.1021/ja8001474

14. Haid S, Marszalek M, Mishra A, Wielopolski M, Teuscher J, Moser JE, Humphry-Baker R, Zakeeruddin SM, Grätzel M, Bäuerle P (2012) Significant improvement of dye-sensitized solar cell performance by small structural modification in $\pi$-conjugated donor-acceptor dyes. Adv Funct Mater 22:1291-1302. https:// doi.org/10.1002/adfm.201102519

15. Sakong C, Kim HJ, Kim SH, Namgoong JW, Park JH, Ryu J-H, Kim B, Ko MJ, Kim JP (2012) Synthesis and applications of new triphenylamine dyes with donor-donor-(bridge)-acceptor structure for organic dye-sensitized solar cells. New J Chem 36:2025-2032. https://doi.org/10.1039/C2NJ40374A

16. Jia J, Zhang Y, Xue P, Zhang P, Zhao X, Liu B, Lu R (2013) Synthesis of dendritic triphenylamine derivatives for dye-sensitized solar cells. Dyes Pigm 96:407-413. https://doi.org/10.1016/j.dyepi g.2012.09.015

17. Ning Z, Zhang Q, Wu W, Pei H, Liu B, Tian H (2008) Starburst triarylamine based dyes for efficient dye-sensitized solar cells. J Org Chem 73:3791-3797. https://doi.org/10.1021/jo800159t

18. Patil DS, Sonigara KK, Jadhav MM, Avhad KC, Sharma S, Soni SS, Sekar N (2018) Effect of structural manipulation in hetero-tri-aryl amine donor-based $\mathrm{D}-\mathrm{A}^{\prime}-\pi-\mathrm{A}$ sensitizers in dye-sensitized solar cells. New J Chem 42:4361-4371. https://doi.org/10.1039/c7nj0 $4620 \mathrm{k}$

19. Yao Y-S, Xiao J, Wang X-S, Deng Z-B, Zhang B-W (2006) Starburst DCM-type red-light-emitting materials for electroluminescence applications. Adv Funct Mater 16:709-718. https://doi. org/10.1002/adfm.200500558

20. Li J, Ma C, Tang J, Lee C-S, Lee S (2005) Novel starburst molecule as a hole injecting and transporting material for organic light-emitting devices. Chem Mater 17:615-619. https://doi. org/10.1021/cm048337d

21. Zhang Q, Ning Z, Tian H (2009) 'Click' synthesis of starburst triphenylamine as potential emitting material. Dyes Pigm 81:80-84. https://doi.org/10.1016/j.dyepig.2008.09.005

22. Liu Q-D, Lu J, Ding J, Day M, Tao Y, Barrios P, Stupak J, Chan K, Li J, Chi Y (2007) Monodisperse starburst oligofluorene-functionalized 4, 4', 4"-tris(carbazol-9-yl)-triphenylamines: their synthesis and deep-blue fluorescent properties for organic light-emitting diode applications. Adv Funct Mater 17:1028-1036. https://doi. org/10.1002/adfm.200600104

23. Pan B, Huang $H$, Yang $X$, Jin J, Zhuang S, Mu G, Wang L (2014) Systematic study of TCTA-based star-shaped host materials by optimizing ratio of carbazole/ diphenylphosphine oxide: achieving both low efficiency roll-off and turn-on voltage for blue PHOLEDs. J Mater Chem C 2:7428-7435. https://doi. org/10.1039/C4TC00951G

24. Kochapradist P, Prachumrak N, Tarsang R, Keawin T, Jungsuttiwong S, Sudyoadsuk T, Promarak V (2013) Multi-triphenylaminesubstituted carbazoles: synthesis, characterization, properties, and applications as hole-transporting materials. Tetrahedron Lett 54:3683-3687. https://doi.org/10.1016/j.tetlet.2013.05.007

25. Zhou G, Wong W-Y, Yao B, Xie Z, Wang L (2007) Triphenylaminedendronized pure red iridium phosphors with superior oled efficiency/color purity trade-offs. Angew Chem Int Ed 46:11491151. https://doi.org/10.1002/anie.200604094

26. Khanasa $T$, Prachumrak N, Rattanawan $R$, Jungsuttiwong S, Keawin T, Sudyoadsuk T, Tuntulani T, Promarak V (2013) 
Bis(carbazol-9-ylphenyl)aniline end-capped oligoarylenes as solution-processed nondoped emitters for full-emission color tuning organic light-emitting diodes. J Org Chem 78:6702-6713. https://doi.org/10.1021/jo4008332

27. Tang X, Liu W, Wu J, Lee C-S, You J, Wang P (2010) Synthesis, crystal structures, and photophysical properties of triphenylaminebased multicyano derivatives. J Org Chem 75:7273-7278. https ://doi.org/10.1021/jo101456v

28. Misra R, Maragani R, Gautam P, Mobin SM (2014) Tetracyanoethylene substituted triphenylamine analogues. Tetrahedron Lett 55:7102-7105. https://doi.org/10.1016/j.tetlet.2014.10.148

29. Li Y, Ren T, Dong W-J (2013) Tuning photophysical properties of triphenylamine and aromatic cyano conjugate-based wavelength-shifting compounds by manipulating intramolecular charge transfer strength. J Photochem Photobiol A Chem 251:1-9. https://doi.org/10.1016/j.jphotochem.2012.10.002

30. Pålsson L-O, Wang C, Batsanov AS, King SM, Beeby A, Monkman AP, Bryce MR (2010) Efficient intramolecular charge transfer in oligoyne-linked donor- $\pi$-acceptor molecules. Chem A Eur J 16:1470-1479. https://doi.org/10.1002/chem.200902099

31. Leriche $P$, Frère $P, C$ ravino $A$, Alévêque $O$, Roncali J (2007) Molecular engineering of the internal charge transfer in thiophenetriphenylamine hybrid $\pi$-conjugated systems. J Org Chem 72:8332-8336. https://doi.org/10.1021/jo701390y

32. Ishow E, Clavier G, Miomandre F, Rebarz M, Buntinx G, Poizat O (2013) Comprehensive investigation of the excited-state dynamics of push-pull triphenylamine dyes as models for photonic applications. Phys Chem Chem Phys 15:13922-13939. https:// doi.org/10.1039/C3CP51480C

33. Pina J, Seixas de Melo JS, Batista RM, Costa SP, Raposo MM (2013) Triphenylamine-benzimidazole derivatives: synthesis, excitedstate characterization, and dft studies. J Org Chem 78:1138911395. https://doi.org/10.1021/jo401803u

34. Katariya SB, Patil D, Rhyman L, Alswaidan IA, Ramasami P, Sekar N (2017) Triphenylamine-based fluorescent NLO phores with ICT characteristics: solvatochromic and theoretical study. J Mol Struct 1150:493-506. https://doi.org/10.1016/j.molst ruc.2017.08.084

35. Yuan WZ, Gong Y, Chen S, Shen XY, Lam JWY, Lu P, Lu Y, Wang Z, Hu R, Xie N, Kwok HS, Zhang Y, Sun JZ, Tang BZ (2012) Efficient solid emitters with aggregation-induced emission and intramolecular charge transfer characteristics: molecular design, synthesis, photophysical behaviors, and OLED application. Chem Mater 24:1518-1528. https://doi.org/10.1021/cm300416y

36. Li H, Chi Z, Xu B, Zhang X, Li X, Liu S, Zhang Y, Xu J (2011) Aggregation-induced emission enhancement compounds containing triphenylamine-anthrylenevinylene and tetraphenylethene moieties. J Mater Chem 21:3760-3767. https://doi.org/10.1039/ COJM02571B

37. Liu Y, Chen S, Lam JWY, Lu P, Kwok RTK, Mahtab F, Kwok HS, Tang BZ (2011) Tuning the electronic nature of aggregation-induced emission luminogens with enhanced hole-transporting property. Chem Mater 23:2536-2544. https://doi.org/10.1021/cm200 3269

38. Wang B, Qian Y (2013) Synthesis and efficient solid-state emission of conjugated donor-acceptor-donor triphenylamine chromophores. New J Chem 37:1402-1407. https://doi. org/10.1039/C3NJ41115J

39. Yang $M, X u ~ D, X i$ W, Wang L, Zheng J, Huang J, Zhang J, Zhou H, Wu J, Tian Y (2013) Aggregation-induced fluorescence behavior of triphenylamine-based schiff bases: the combined effect of multiple forces. J Org Chem 78:10344-10359. https://doi. org/10.1021/jo401719c

40. Zhao X, Xue P, Wang K, Chen P, Zhang P, Lu R (2014) Aggregationinduced emission of triphenylamine substituted cyanostyrene derivatives. New J Chem 38:1045-1051. https://doi.org/10.1039/ C3NJ01343J

41. Ning Z, Chen Z, Zhang Q, Yan Y, Qian S, Cao Y, Tian H (2007) Aggregation-induced emission (AIE)-active starburst triarylamine fluorophores as potential non-doped red emitters for organic light-emitting diodes and $\mathrm{Cl} 2$ gas chemodosimeter. Adv Funct Mater 17:3799-3807. https://doi.org/10.1002/adfm.20070 0649

42. Zheng Z, Yu Z, Yang M, Jin F, Zhang Q, Zhou H, Wu J, Tian Y (2013) Substituent group variations directing the molecular packing, electronic structure, and aggregation-induced emission property of isophorone derivatives. J Org Chem 78:3222-3234. https ://doi.org/10.1021/jo400116j

43. Wang L, Shen Y, Zhu Q, Xu W, Yang M, Zhou H, Wu J, Tian Y (2014) Systematic study and imaging application of aggregationinduced emission of ester-isophorone derivatives. J Phys Chem C 118:8531-8540. https://doi.org/10.1021/jp412279m

44. Haidekker MA, Theodorakis EA (2007) Molecular rotors-fluorescent biosensors for viscosity and flow. Org Biomol Chem 5:1669-1678. https://doi.org/10.1039/b618415d

45. Lakowicz JR, Masters BR (2008) Principles of fluorescence spectroscopy, 3rd edn. Springer, Berlin. https://doi. org/10.1117/1.2904580

46. Jacobson A, Petric A, Hogenkamp D, Sinur A, Barrio JR (1996) 1, 1-Dicyano-2-[6-(dimethylamino)naphthalen-2-yl]propene (DDNP): a solvent polarity and viscosity sensitive fluorophore for fluorescence microscopy. J Am Chem Soc 118:5572-5579. https://doi.org/10.1021/ja9543356

47. Zhou F, Shao J, Yang Y, Zhao J, Guo H, Li X, Ji S, Zhang Z (2011) Molecular rotors as fluorescent viscosity sensors: molecular design, polarity sensitivity, dipole moments changes, screening solvents, and deactivation channel of the excited states. Eur J Org Chem 2011:4773-4787. https://doi.org/10.1002/ejoc.20110 0606

48. Gupta KSV, Zhang J, Marotta G, Reddy MA, Singh SP, Islam A, Han L, De Angelis F, Chandrasekharam M, Pastore M (2015) Effect of the anchoring group in the performance of carbazolephenothiazine dyads for dye-sensitized solar cells. Dyes Pigm 113:536-545. https://doi.org/10.1016/j.dyepig.2014.09.032

49. Manoharan S, Asiri AM, Anandan S (2016) Impact of anchoring groups for improving the binding nature of organic dyes toward high efficient dye sensitized solar cells. Sol Energy 126:22-31. https://doi.org/10.1016/j.solener.2015.12.047

50. Wykes M, Odobel F, Adamo C, Ciofini I, Labat F (2016) Anchoring groups for dyes in p-DSSC application: insights from DFT. J Mol Model. https://doi.org/10.1007/s00894-016-3155-1

51. Yang YS, Do Kim H, Ryu JH, Kim KK, Park SS, Ahn KS, Kim JH (2011) Effects of anchoring groups in multi-anchoring organic dyes with thiophene bridge for dye-sensitized solar cells. Synth Met 161:850-855. https://doi.org/10.1016/j.synth met.2011.02.012

52. Patil D, Jadhav M, Avhad K, Gawale Y, Sekar N (2018) NIR emitting new $N, N$-diethylaniline based NLOphoric $D-\pi-A$ and $D-A^{\prime}-\pi-A$ dyes: photophysical properties, viscosity sensitivity and DFT studies. J Lumin 204:436-447. https://doi.org/10.1016/j.jlumi n.2018.08.031

53. Baktash A, Khoshnevisan B, Sasani A, Mirabbaszadeh K (2016) Effects of carboxylic acid and phosphonic acid anchoring groups on the efficiency of dye sensitized solar cells: a computational study. Org Electron phys Mater Appl 33:207-212. https ://doi.org/10.1016/j.orgel.2016.03.013

54. Higashino T, Fujimori Y, Sugiura K, Tsuji Y, Ito S, Imahori H (2015) Tropolone as a high-performance robust anchoring group for dye-sensitized solar cells. Angew Chem Int Ed. https://doi. org/10.1002/anie.201502951 
55. Keawin T, Tarsang R, Sirithip K, Prachumrak N, Sudyoadsuk T, Namuangruk S, Roncali J, Kungwan N, Promarak V, Jungsuttiwong S (2017) Anchoring number-performance relationship of zinc-porphyrin sensitizers for dye-sensitized solar cells: a combined experimental and theoretical study. Dyes Pigm 136:697706. https://doi.org/10.1016/j.dyepig.2016.09.035

56. Suresh T, Chitumalla RK, Hai NT, Jang J, Lee TJ, Kim JH (2016) Impact of neutral and anion anchoring groups on the photovoltaic performance of triphenylamine sensitizers for dyesensitized solar cells. RSC Adv. https://doi.org/10.1039/c6ra0 0636a

57. Kryman MW, Nasca JN, Watson DF, Detty MR (2016) Selenorhodamine dye-sensitized solar cells: influence of structure and surface-anchoring mode on aggregation, persistence, and photoelectrochemical performance. Langmuir 32:1521-1532. https://doi.org/10.1021/acs.langmuir.5b04275

58. Avhad K, Jadhav M, Patil D, Chowdhury TH, Islam A, Bedja I, Sekar $N$ (2019) Rhodanine-3-acetic acid containing $D-\pi-A$ push-pull chromophores: effect of methoxy group on the performance of dye-sensitized solar cells. Org Electron 65:386-393. https://doi. org/10.1016/J.ORGEL.2018.11.041

59. Ju J, Chen W (2014) Synthesis of highly fluorescent nitrogendoped graphene quantum dots for sensitive, label-free detection of Fe (III) in aqueous media. Biosens Bioelectron 58:219225. https://doi.org/10.1016/j.bios.2014.02.061

60. Patil D, Jadhav M, Avhad K, Chowdhury TH, Islam A, Bedja I, Sekar N (2018) A new class of triphenylamine-based novel sensitizers for DSSCs: a comparative study of three different anchoring groups. New J Chem 42:11555-11564. https://doi.org/10.1039/ c8nj01029c

61. Selivanova DG, Shklyaeva EV, Shavrina TV, Abashev GG (2014) New thiophene- and phenothiazine-containing chalcones: synthesis, and electrochemical properties. Russ J Org Chem 50:1213-1217. https://doi.org/10.1134/S1070428014080272

62. Lippert E (1957) Spektroskopische bestimmung des dipolmomentes aromatischer verbindungen im ersten angeregten singulettzustand. Zeitschrift für Elektrochemie Berichte der Bunsengesellschaft für Phys Chemie 61:962-975. https://doi. org/10.1002/bbpc.19570610819

63. McRae EG (1957) Theory of solvent effects on molecular electronic spectra. Freq Shifts J Phys Chem 61:562-572. https://doi. org/10.1021/j150551a012

64. Ravi M, Samanta A, Radhakrishnan TP (1994) Excited state dipole moments from an efficient analysis of solvatochromic stokes shift data. J Phys Chem 98:9133-9136. https://doi.org/10.1021/ j100088a007

65. Reichardt C (1994) Solvatochromic dyes as solvent polarity indicators. Chem Rev 94:2319-2358. https://doi.org/10.1021/cr000 32a005

66. Gaussian 09 Citation

67. Becke AD (1993) A new mixing of Hartree-Fock and local density-functional theories. J Chem Phys 98:1372. https://doi. org/10.1063/1.464304
68. Lee C, Yang W, Parr RG (1988) Development of the Colle-Salvetti correlation-energy formula into a functional of the electron density. Phys Rev B 37:785-789. https://doi.org/10.1103/PhysR evB.37.785

69. Abbotto A, Beverina L, Bradamante $S$, Facchetti A, Klein C, Pagani GA, Redi-abshiro M, Wortmann R (2003) A distinctive example of the cooperative interplay of structure and environment in tuning of intramolecular charge transfer in second-order nonlinear optical chromophores. Chem A Eur J 9:1991-2007. https://doi. org/10.1002/chem.200204356

70. Momicchioli F, Ponterini G, Vanossi D (2008) First- and secondorder polarizabilities of simple merocyanines. an experimental and theoretical reassessment of the two-level model. J Phys Chem A 112:11861-11872

71. Oudar JL, Chemla DS (1977) Hyperpolarizabilities of the nitroanilines and their relations to the excited state dipole moment. J Chem Phys 66:2664-2668. https://doi.org/10.1063/1.434213

72. Kwon O, Jazbinsek M, Seo J, Kim P, Choi E, Sup Y, Günter P (2010) First hyperpolarizability orientation in asymmetric pyrrolebased polyene chromophores. Dyes Pigm 85:162-170. https:// doi.org/10.1016/j.dyepig.2009.10.019

73. Cbeng L, Tam W, Stevenson SH, Meredith GR, Marder SR (1991) Experimental investigations of organic molecular nonlinear optical polarizabilities 1 methods and results on benzene and stilbene derivatives. J Phys Chem 95:10631-10643

74. Yamashita M, Kikuma S, Yamaoka Y, Murakami H, Morita R, Shigekawa H (1999) Nonresonant femtosecond second hyperpolarizabilities of intramolecular charge-transfer molecules with great excited-and ground-state dipole-moment differences. Appl Phys Lett 75:28. https://doi.org/10.1063/1.124266

75. Isborn CM, Leclercq A, Vila FD, Dalton LR, Brédas JL, Eichinger $\mathrm{BE}$, Robinson BH (2007) Comparison of static first hyperpolarizabilities calculated with various quantum mechanical methods. J Phys Chem A 111:1319-1327. https://doi.org/10.1021/jp064 096g

76. Vidya S, Ravikumar C, Hubert Joe I, Kumaradhas P, Devipriya B, Raju K (2011) Vibrational spectra and structural studies of nonlinear optical crystal ammonium D, L-tartrate: a density functional theoretical approach. J Raman Spectrosc 42:676-684. https://doi.org/10.1002/jrs.2743

77. Kuzyk MG (2006) Fundamental limits of all nonlinear-optical phenomena that are represntable by a second-order nonlinear susceptibility. J Chem Phys 125:154108. https://doi. org/10.1063/1.2358973

Publisher's Note Springer Nature remains neutral with regard to jurisdictional claims in published maps and institutional affiliations. 